\title{
Effectiveness of a Planned Teaching Program on the Knowledge of Staff Nurses with Regard to the Nutritional Requirements of Patients with Chronic Kidney Disease
}

\author{
${ }^{1}$ Department of Community Health Nursing, Nitte Usha Institute of \\ Nursing Sciences, Deralakatte, Mangaluru, Karnataka, India \\ ${ }^{2}$ Nitte Usha Institute of Nursing Sciences, Deralakatte, Mangaluru, \\ Karnataka, India \\ 3 International Institute for Population Sciences, Deonar, Mumbai, \\ Maharashtra, India
}

Sarita Telma Fernandes ${ }^{1}$ Fatima Dsilva ${ }^{2}$ Sushma Marita Dsouza ${ }^{3}$

\begin{abstract}
Address for correspondence Fatima Dsilva, MSc, PhD, Nitte Usha Institute of Nursing Sciences, Deralakatte, Mangaluru, Karnataka 575018, India (e-mail: ftds_1970@rediffmail.com).
\end{abstract}

J Health Allied Sci Nu 2021;11:188-192.

\begin{abstract}
Objective This study was done to evaluate the effectiveness of a planned teaching program on the knowledge of staff nurses with regard to the nutritional requirements of patients with chronic kidney disease.

Methods Uncontrolled before-and-after study was conducted among staff nurses of a hospital. Convenient sampling was used to select the participants. Pretest knowledge was assessed using a structured questionnaire among staff nurses. After the pretest, the experimental group was administered a planned teaching program for 60 minutes. On the 7th, 14th, 21st, and 28th day the posttests were conducted by delivering the same tool to determine the posttest level of knowledge after the administration of the planned teaching program.

Results The staff nurses' pretest knowledge scores reveal that the majority (77.5\%) had an average knowledge level and $10 \%$ had poor knowledge levels. The effectiveness

Keywords

- chronic kidney disease

- staff nurses

- knowledge

- planned teaching program of the planned teaching program showed that the mean pretest knowledge score of the staff nurses $\left(\bar{x}_{1}=16.10\right)$ was significantly lower than the mean posttest knowledge scores of the participants $\left(\bar{x}_{2}=20.78, \bar{x}_{3}=24.35, \bar{x}_{4}=24.20\right.$, and $\left.\bar{x}_{5}=28.75\right)$.

Conclusion In this study, the planned teaching program was found to be efficient on the knowledge level of staff nurses regarding the nutritional requirements of patients with chronic kidney disease.
\end{abstract}

\section{Introduction}

Chronic kidney disease (CKD) is a continuous and progressive deterioration of kidney function over several years, which is characterized by the formation of fibrotic tissue and loss of normal kidney structure. As a result of this, kidneys fail to

published online May 14, 2021
DOI https://doi.org/

$10.1055 / \mathrm{s}-0041-1730106$

ISSN $2582-4287$ process the waste in the blood and other functions. Initial stages of CKD are characterized by slight decreased or normal glomerular filtration rate (GFR) and later it leads to chronic renal failure (CRF) or end-stage renal disease (ESRD). ${ }^{1}$

ESRD denotes the end of the CKD continuum. It is an overwhelming medical, social, and economic problem for the

(c) 2021. Nitte (Deemed to be University).

This is an open access article published by Thieme under the terms of the Creative Commons Attribution-NonDerivative-NonCommercial-License, permitting copying and reproduction so long as the original work is given appropriate credit. Contents may not be used for commercial purposes, or adapted, remixed, transformed or built upon. (https://creativecommons.org/licenses/by-nc-nd/4.0/).

Thieme Medical and Scientific Publishers Pvt. Ltd. A-12, 2nd Floor, Sector 2, Noida-201301 UP, India 
patients, their families, and for the whole country. ${ }^{2}$ CKD is a significant component of chronic noncommunicable diseases (NCDs). ${ }^{3}$ It is contributing to the highest rates of mortality and morbidity. ${ }^{4}$

About $10 \%$ of the population worldwide is affected by CKD, and millions die every year due to unaffordable treatment. ${ }^{5}$ As per the 2017 Global Burden of Disease study, in 2017, worldwide 697.5 million cases of CKD have been reported and mortality was 1.2 million. ${ }^{6}$ CKD patients have risk factors for atherosclerosis, dyslipidemia, hypertension, and insulin resistance which can be controlled by a fat, sodium, and sugar-restricted but high-fiber diet. ${ }^{7}$

According to Bergstrom, CKD entails variations in calorie, protein, and micronutrient intake. These may contribute to the high incidence of protein-energy malnutrition (PEM) and the most critical risk factors for increased morbidity and mortality in ESRD. ${ }^{8}$ At the same time, the ingestion of excessive potassium, phosphorus, sodium, and fluid may have hostile effects on fluid balance and other complications caused by electrolyte instabilities. ${ }^{9}$ Hence management of the nutritional aspects displays many challenges.

Due to extensive changes in lifestyle as well as diet and fluid restrictions, CKD has caused the involvement of families along with patients and dietitians. ${ }^{10}$ Moreover, the assessment of nutritional requirements and nutritional modifications requires the involvement of a nephrologist and nurses on a patient-to-patient basis depending upon the underlying comorbid diseases and conditions.

Studies have conveyed that 33 to $50 \%$ of hemodialysis patients were noncompliant with fluid restriction regimens, which challenges the effectiveness of treatment, resulting in inconsistent progress of the disease and a higher chance of complications. Researchers have concluded that interventions that encourage fluid intake compliance are vital for these patients. ${ }^{11}$

Nurses are recognized as being more passionate about constantly working in hospitals, particularly in renal dialysis. It is a very specialized field because the health care team members give special care to fulfill the basic needs of renal patients. ${ }^{12}$

The current study was done to determine the effectiveness of a planned teaching program on the knowledge of staff nurses with regard to the nutritional requirements of patients with CKD.

\section{Methods}

\section{Study Design, Settings, Participants}

This study was conducted between April 2018 and May 2018 in a hospital by using uncontrolled before-and-after study design. A total of 40 staff nurses working at the hospital were selected using a convenient sampling technique.

\section{Eligibility Criteria}

The inclusion criterion was staff nurses who were willing to participate in this study. The exclusion criterion was staff nurses who had already undergone nutritional training programs.

\section{Data Collection Methods}

The planned teaching program was given to 40 staff nurses working at the hospital during the data collection period. The data collection instruments included demographic proforma and a structured questionnaire on a renal diet. Formal written permission was taken from the medical superintendent, the nursing superintendent, and the head of the department (HOD) of nephrology. Informed consent was obtained from the staff nurses individually after explaining the objectives and purpose of the study. The pretest was done by administering instruments like demographic proforma and structured questionnaire on a renal diet among the staff nurses. The average time taken to complete this was 10 to 15 minutes. After the pretest, the staff nurses underwent planned teaching for 60 minutes with the help of Microsoft PowerPoint slides. Followed by that the posttest was conducted four times on the 7th, 14th, 21st, and 28th day by administering the same tool to determine the posttest level of knowledge after the administration of PTP. The sequence of data collection was shown in - Fig. 1.

\section{Ethical Permission}

Ethical permission for the study was obtained from the ethics committee on January 1, 2018.The registration number was NUINS/CON/NU/IEC/2017-18. Participation was voluntary and informed consent was obtained from all the participants after the purpose and objectives of the study were explained to them with the participant information sheet. Data confidentiality was guaranteed.

\section{Analysis}

Data analysis was done by using Statistical Package for Social Sciences 20 SPSS-20 (SPSS Inc., Chicago, IL) software. Descriptive statistics and inferential statistics were used for analyzing sociodemographic data and structured questionnaires. Analysis of variance (ANOVA) test was done to evaluate the effectiveness of the planned teaching program.

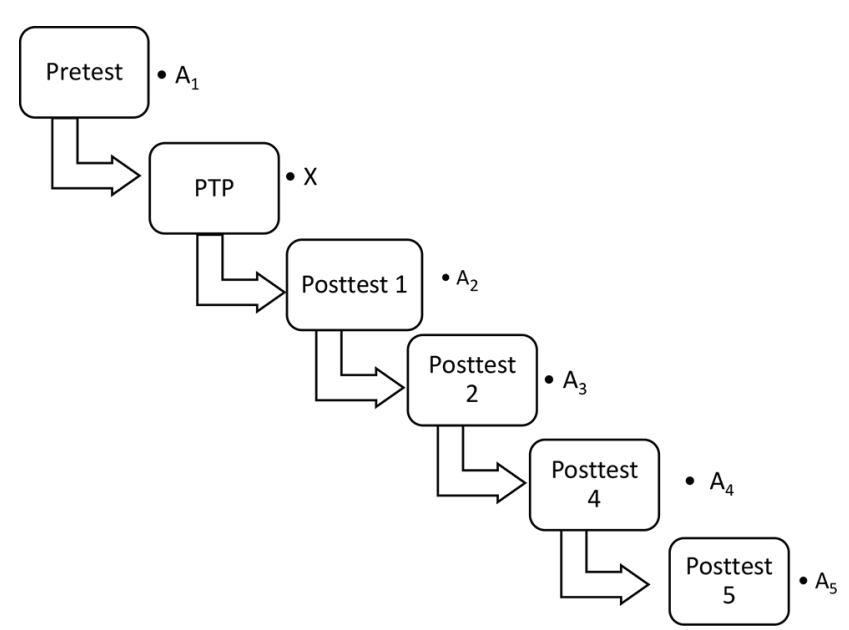

Fig. 1 The sequence of data collection.A1-pretest (assessment of knowledge of staff nurses before the planned teaching program [PTP]); $X$-intervention of PTP on renal diet; $\mathbf{A} 2$-posttest 1 (7th-day assessment of knowledge of staff nurses after PTP); 03-posttest 2 (14th-day assessment of knowledge of staff nurses after PTP); 04-posttest 3 (21st-day assessment of knowledge of staff nurses after PTP); 05-posttest 4 (28th-day assessment of knowledge of staff nurses after PTP). 


\section{Results}

The data collected from the subject were organized and are presented in the following sections.

\section{Description of Sample Characteristics}

The data obtained on sample characteristics were analyzed using descriptive statistics. The frequency and percentage of the staff nurses by the demographic characteristics are presented in - Table 1.

The distribution of staff nurses according to age depicts that the mean age of the staff nurses was 25.78 years. According to the gender, data reveal that $92.5 \%$ were females, and $7.5 \%$ were males. The distribution of the staff nurses based on qualification reveals that majority $57.5 \%$ of them have completed general nursing and midwifery, $40 \%$ had completed bachelor's degree in nursing sciences, and only $2.5 \%$ had completed postbasic nursing.

\section{Distribution of the Level of Knowledge Among the Staff Nurses}

- Table 2 depicts the distribution of knowledge level of staff nurses in which good knowledge score was seen among $12.5 \%$ staff nurses during pretest, whereas the majority had good knowledge score in posttest, that is, 7th day posttest $-60 \%$, 14 th day posttest $-87.5 \%, 21$ st day posttest- $77.5 \%$, and 28 th day posttest-97.5\% . In pretest majority $(77.5 \%)$ of staff nurses had average knowledge score and $2.5 \%$ had average knowledge score in the 28th day posttest. Lastly, poor knowledge score was seen among $10 \%$ of staff nurses in pretest, whereas none of the staff nurses had poor knowledge score in the 21st and 28th days of posttest.

Table 1 Distribution of demographic characteristics of the staff nurse

\begin{tabular}{|l|l|l|l|}
\hline$(n=40)$ & Variables & Frequency & Percentage \\
\hline \multirow{3}{*}{ Age (y) } & $22-24$ & 19 & 47.5 \\
\cline { 2 - 4 } & $25-27$ & 14 & 35.0 \\
\cline { 2 - 4 } & $28-56$ & 7 & 17.5 \\
\hline \multirow{3}{*}{ Gender } & Female & 37 & 92.5 \\
\cline { 2 - 4 } & Male & 3 & 7.5 \\
\hline \multirow{3}{*}{ Qualification } & GNM & 23 & 57.5 \\
\cline { 2 - 4 } & BSc & 16 & 40.0 \\
\cline { 2 - 4 } & Post-BSc & 1 & 2.5 \\
\hline
\end{tabular}

Abbreviations: GNM, general nursing and midwifery; BSc, bachelor of science; $n$, number.

\section{Effectiveness of Planned Teaching Program by Using Repeated Measures of ANOVA}

- Table 3 shows the mean pretest knowledge score of the staff nurses $\left(\mathrm{x}_{1}^{-}=16.10\right)$ was significantly lower than their mean posttest knowledge scores $\left(\mathrm{x}_{2}^{-}=20.78, \mathrm{x}_{3}^{-}=24.35, \mathrm{x}_{4}^{-}\right.$ $=24.20$, and $x_{5}^{-}=28.75$ ). In the repeated measures ANOVA, $p$-value is less than 0.05 , and hence there was a significant difference in the level of knowledge of staff nurses after the planned teaching program.

\section{Comparison of Pretest and Posttest 4 Questionwise Answers}

Questionwise comparison of knowledge among the staff nurses between pretest and posttest 4 was depicted in - Table 4. It indicates that staff nurses had good knowledge in posttest 4 as compared with pretest.

Significant changes in the knowledge level was seen in posttest 1 and posttest 4 , indicating the need for reinforced teaching and better retention of knowledge.

\section{Discussion}

CKD is a significant health issue in various parts of the world. Nowadays medical management is not the only effective treatment of CKD, the patient with CKD also needs acute nursing care to prevent complications and decrease the stress and anxieties of dealing with a serious illness. Nursing care is focused toward assessing the fluid status and identifying possible sources of imbalance, executing a dietary program to ensure appropriate nutritional intake within the limits of the treatment regimen, and promoting positive feelings of the patients by encouraging increased self-care and greater independence. ${ }^{13}$

Patients with CKD have nutritional needs, different from healthy individuals. The identification of these dietary

Table 3 Effectiveness of planned teaching program on knowledge levels among the staff nurses by using repeated measures analysis of variance (ANOVA)

\begin{tabular}{|l|l|l|l|l|}
\hline $\begin{array}{l}\text { Variables } \\
(\boldsymbol{n}=\mathbf{4 0})\end{array}$ & Mean & $\begin{array}{l}\text { Standard } \\
\text { deviation }\end{array}$ & $\mathbf{F}$ & $\boldsymbol{p}$-Value \\
\hline Pretest & 16.10 & 3.68 & \multirow{2}{*}{56.83} & $<0.001$ \\
\cline { 1 - 3 } Posttest1 & 20.78 & 5.38 & & \\
\cline { 1 - 3 } Posttest 2 & 24.35 & 4.061 & & \\
\cline { 1 - 3 } Posttest 3 & 24.20 & 4.177 & & \\
\cline { 1 - 3 } Posttest 4 & 28.75 & 3.410 & & \\
\hline
\end{tabular}

Note: $p$-Value $\leq 0.05$ considered significant.

Table 2 Distribution of the level of knowledge among the staff nurses

\begin{tabular}{|l|l|l|l|l|l|}
\hline Knowledge $(\boldsymbol{n}=\mathbf{4 0})$ & Pretest & Posttest 1 & Posttest 2 & Posttest 3 & Posttest 4 \\
\hline Poor $(1-10)$ & $4(10)$ & $2(5.0)$ & $1(2.5)$ & - & - \\
\hline Average $(11-20)$ & $31(77.5)$ & $14(35.0)$ & $4(10.0)$ & $9(22.5)$ & $1(2.5)$ \\
\hline Good $(21-32)$ & $5(12.5)$ & $24(60)$ & $35(87.5)$ & $31(77.5)$ & $39(97.5)$ \\
\hline
\end{tabular}


requirements mandates a thorough understanding of various physiologic and pathologic processes linked to the renal system. ${ }^{14} \mathrm{As}$ staff nurses play a significant role in CKD management by directing the dietary regulations through patient education, staff nurses should have adequate knowledge regarding the nutritional requirements of patients with CKD. A planned teaching program for staff nurses has an influence on increasing the knowledge level.

Majority of studies have shown that nurses are found to have an inadequate level of nutritional knowledge and that there is a superior need for nutrition education..$^{15} \mathrm{~A}$ descriptive cross-sectional study has revealed that $\sim 70.6 \%$ of staff nurses had a fair knowledge score, $17.6 \%$ had a good knowledge score, and $11.8 \%$ had a low knowledge score. ${ }^{16}$ The dearth of knowledge about nutritional modification is an actual concern, as these health care workers many a time provide information to the patients on their nutrition. Hence, interventions are essential to guarantee that the information they pass on to their patients is precise and up-to-date. ${ }^{17} \mathrm{An}$ other study revealed that only $38 \%$ of nurses were aware of the requirement of a higher protein diet for dialysis patients. ${ }^{18}$

The majority (59.4\%) of the health care workers had low nutrition knowledge in a cross sectional study conducted in Tanzania with a mean score of 9.8. ${ }^{17}$ In the current study, the mean pretest score was 16.10 and it increased to 20.78 in posttest $1,24.35$ in posttest $2,24.20$ in posttest 3 , and 28.75 in posttest 4 . The result revealed that there is a significant increase in the level of knowledge after providing PTP for staff nurses.

The current study result shows that the obtained $p$-value is less than 0.05 for posttest 1 and posttest 4 , indicating a significant difference in knowledge before and after the PTP.

Table 4 Questionwise comparison of pretest and posttest 4 nutritional knowledge among the staff nurses

\begin{tabular}{|c|c|c|c|c|}
\hline \multirow{2}{*}{$\begin{array}{l}\text { Question number } \\
(n=40)\end{array}$} & \multicolumn{2}{|r|}{ Pretest } & \multicolumn{2}{|r|}{ Posttest 4} \\
\hline & Frequency & Percentage (\%) & Frequency & Percentage (\%) \\
\hline 1 & 11 & 27.5 & 40 & 100 \\
\hline 2 & 31 & 77.5 & 40 & 100 \\
\hline 3 & 13 & 32.5 & 39 & 97.5 \\
\hline 4 & 12 & 30 & 40 & 100 \\
\hline 5 & 26 & 65 & 38 & 95 \\
\hline 6 & 17 & 42.5 & 26 & 65 \\
\hline 7 & 34 & 85 & 38 & 95 \\
\hline 8 & 31 & 77.5 & 38 & 95 \\
\hline 9 & 28 & 70 & 35 & 87.5 \\
\hline 10 & 9 & 22.5 & 27 & 67.5 \\
\hline 11 & 25 & 62.5 & 35 & 87.5 \\
\hline 12 & 11 & 27.5 & 39 & 97.5 \\
\hline 13 & 7 & 17.5 & 36 & 90 \\
\hline 14 & 24 & 60 & 32 & 80 \\
\hline 15 & 25 & 62.5 & 35 & 87.5 \\
\hline 16 & 29 & 72.5 & 35 & 87.5 \\
\hline 17 & 17 & 42.5 & 31 & 77.5 \\
\hline 18 & 17 & 42.5 & 31 & 77.5 \\
\hline 19 & 34 & 85 & 34 & 85 \\
\hline 20 & 11 & 27.5 & 38 & 95 \\
\hline 21 & 18 & 45 & 36 & 90 \\
\hline 22 & 10 & 25 & 38 & 95 \\
\hline 23 & 13 & 32.5 & 37 & 92.5 \\
\hline 24 & 25 & 62.5 & 37 & 92.5 \\
\hline 25 & 16 & 40 & 35 & 87.5 \\
\hline 26 & 11 & 27.5 & 34 & 85 \\
\hline 27 & 25 & 62.5 & 40 & 100 \\
\hline 28 & 35 & 87.5 & 36 & 90 \\
\hline 29 & 15 & 37.5 & 37 & 92.5 \\
\hline 30 & 23 & 57.5 & 37 & 92.5 \\
\hline 31 & 28 & 70 & 39 & 97.5 \\
\hline 32 & 13 & 32.5 & 38 & 95 \\
\hline
\end{tabular}


Moreover, the results indicate that nursing staff should be given PTP on the nutritional requirement of patients with CKD, which in total helps to balance the nutritional requirement of CKD patients.

\section{Conclusion}

CKD is a progressive loss of kidney function over several years, leading to ESRD where the patient needs either dialysis or transplantation for survival. It is imperative to consider the diet to keep a balanced level of electrolytes, minerals, and fluid in the body. Staff nurses are giving care to the patients and hence they should be knowledgeable about what diet should be recommended for CKD patients.

\section{Funding}

None.

\section{Conflict of interest}

None declared.

\section{Acknowledgments}

The authors would like to thank all the staff nurses who participated in this study. They thank KSHEMA Hospital, Nitte Usha Institute of Nursing Sciences, and Nitte Deemed to be University for their support.

\section{References}

1 Kumela Goro K, Desalegn Wolide A, Kerga Dibaba F, et al. Patient awareness, prevalence, and risk factors of chronic kidney disease among diabetes mellitus and hypertensive patients at Jimma University Medical Center, Ethiopia. Bio Med Res Int 2019;2019:2383508

2 Ayodele OE, Alebiosu CO. Burden of chronic kidney disease: an international perspective. Adv Chronic Kidney Dis 2010;17(3):215-224

3 Modi GK, Jha V.The incidence of end-stage renal disease in India: a population-based study. Kidney Int 2006;70(12):2131-2133

4 Thorp ML, Eastman L, Smith DH, Johnson ES. Managing the burden of chronic kidney disease. Dis Manag 2006;9(2):115-121

5 Day WK. Chronic kidney disease. Accessed April 21, 2021 at: http://www.worldkidneyday.org/faqs/chronic-kidney-disease/. Published 2015
6 GBD Chronic Kidney Disease Collaboration. Global, regional, and national burden of chronic kidney disease, 1990-2017: a systematic analysis for the Global Burden of Disease Study 2017. Lancet 2020 (e-pub ahead of print).;doi:10.1016/S0140-6736(20)30045-3

7 Manual M. Protein energy under nutrition. Accessed April 21, 2021 at: http://www.merck.com/mmpe/sec01/ch002b.html. Published 2010

8 Bergstrom J, Nutritional requirements of hemodialysis patients. In: Mitch WE, Klahr S, eds. Nutrition and the Kidney. 2nd edn. London, United Kingdom: Little, Brown and Co., 1993 245-249

9 Zeier M. Risk of mortality in patients with end-stage renal disease: the role of malnutrition and possible therapeutic implications. Horm Res 2002;58(3(Suppl 3) :30-34

10 Ahrari S, Moshki M, Bahrami M. The relationship between social support and adherence of dietary and fluids restrictions among hemodialysis patients in Iran. J Caring Sci 2014;3(1):11-19

11 Long JM, Kee CC, Graham MV, Saethang TB, Dames FD. Medication compliance and the older hemodialysis patient. ANNA J 1998;25(1):43-49, discussion 50-52

12 Rowland HS, Rowland BL, Nursing Administration Handbook. 2nd ed. Rockville, MA: Aspen Systems Corporation; 1985

13 Day RA, Pauline P, Williams B, Smeltzer SC, Bare BG. Brunner and Suddharth's Textbook of Canadian Medical-Surgical Nursing. 2nd ed. Philadelphia, PA: LippincotWilliams and Wilkins; 20091443

14 Bajwa SJ, Kwatra IS. Nutritional needs and dietary modifications in patients on dialysis and chronic kidney disease. J Med Nutr Nutraceut 2013;2(1):46-51

15 Yalcin N, Cihan A, Gundogdu H, Ocakci A. Nutrition knowledge level of nurses. Health Sci J 2013;7(1):99-108

16 Rasheed HA, Aziz NG, Osman GA, Younis YM. Nurses' knowledge of the nutritional management of renal failure in Erbil City, Kurdistan Region, Iraq. Zanco J Med Sci 2018;22(3):385-393

17 Munuo AE, Mugendi BW, Kisanga OA, Otieno GO. Nutrition knowledge, attitudes and practices among healthcare workers in management of chronic kidney diseases in selected hospitals in Dar es Salaam, Tanzania; a cross-sectional study. BMC Nutr 2016;2(1):1-7

18 Yin OS. Knowledge in renal nutrition of medical doctors and nursing staff. Kidney Res Clin Pract 2012;31(2):A63 